STUDY OF THERMAL SENSITIVITY AND THERMAL EXPLOSION VIOLENCE OF ENERGETIC MATERIALS IN THE LLNL ODTX SYSTEM

P. C. HSU, G. Hust, C. May, M. Howard, S. K. Chidester, H. K. Springer, J. L. Maienschein

August 9, 2011

The APS Shock Compression of Condensed Matter Chicago, IL, United States June 26, 2011 through July 1, 2011 
This document was prepared as an account of work sponsored by an agency of the United States government. Neither the United States government nor Lawrence Livermore National Security, LLC, nor any of their employees makes any warranty, expressed or implied, or assumes any legal liability or responsibility for the accuracy, completeness, or usefulness of any information, apparatus, product, or process disclosed, or represents that its use would not infringe privately owned rights. Reference herein to any specific commercial product, process, or service by trade name, trademark, manufacturer, or otherwise does not necessarily constitute or imply its endorsement, recommendation, or favoring by the United States government or Lawrence Livermore National Security, LLC. The views and opinions of authors expressed herein do not necessarily state or reflect those of the United States government or Lawrence Livermore National Security, LLC, and shall not be used for advertising or product endorsement purposes. 


\title{
STUDY OF THERMAL SENSITIVITY AND THERMAL EXPLOSION VIOLENCE OF ENERGETIC MATERIALS IN THE LLNL ODTX SYSTEM
}

\author{
P. C. Hsu, G. Hust, C. May, M. Howard, S. K. Chidester, H. K. Springer \\ and J. L. Maienschein \\ Lawrence Livermore National Laboratory \\ Livermore, CA 94550
}

\begin{abstract}
Some energetic materials may explode at fairly low temperatures and the violence from thermal explosion may cause a significant damage. Thus it is important to understand the response of energetic materials to thermal insults for safe handling and storage of energetic materials. The One Dimensional Time to Explosion (ODTX) system at the Lawrence Livermore National Laboratory can measure times to explosion, lowest explosion temperatures, and determine kinetic parameters of energetic materials. Samples of different configurations can be tested in the system. The ODTX testing can also generate useful data for determining thermal explosion violence of energetic materials. We also performed detonation experiments of LX-10 in aluminum anvils to determine the detonation violence and validated the Zerilli Armstrong aluminum model. Results of the detonation experiments agreed well with the model prediction.
\end{abstract}

Key words: thermal safety, thermal sensitivity, thermal explosion violence, detonation violence, LX-10. PACS: 65.40.De, 65.60.+a.

\section{INTRODUCTION}

Thermal incidents such as fires in storage bunkers, magazines, and transportation carriers (trucks, aircrafts, ships) would expose energetic materials to unexpected heat that may cause thermal explosion. Before deploying fire fighting personnel to extinguish the fire, the first responders would need to know whether the energetic materials would explode and how much structural damage the explosion may cause. Thus it is important to know the time to thermal explosion of energetic materials at elevated temperature and thermal explosion violence. The One Dimensional Time to Explosion (ODTX) system has been used for 4 decades at LLNL as a tool to study thermal sensitivity and thermal explosion of energetic materials ${ }^{1,2,3,4}$. The ODTX testing generates time to thermal explosion data that allows for the calculation of activation energy and frequency factor of thermal explosion. The calculation is represented by a single-step Prout-Tompkins (Arrhenius) model. They are useful data for simulation and modeling in the ALE3D (Arbitrary Lagrangian-Eulerian in Three Dimensions) computer code. The computer code has been used in many applications to predict both the timing and violence of thermal ignition events. The ODTX system can also measure the threshold temperature $\left(\mathrm{T}_{\mathrm{ii}}\right)$ for thermal explosion to occur. Determining the value of $\mathrm{T}_{\mathrm{li}}$ is very important for safe storage and handling.

Violence from thermal explosion is important for the overall assessment of an energetic material. Ideally, high detonation violence for performance and low thermal explosion violence for thermal safety are desirable. The ODTX system is an inexpensive tool that allows for a quick estimate 
of thermal explosion violence by the cavity size expansion.

\section{EXPERIMENTS}

The detail description of the LLNL ODTX system can be found elsewhere ${ }^{1,4}$. Energetic materials in any sample configurations (except gaseous samples) can be tested in the ODTX system. An aluminum shell is used to hold powder samples, pasty samples, or liquid samples. Pressed and cast samples (Figure 1) are delivered to the cavity of aluminum anvils directly without the use of the aluminum shell.

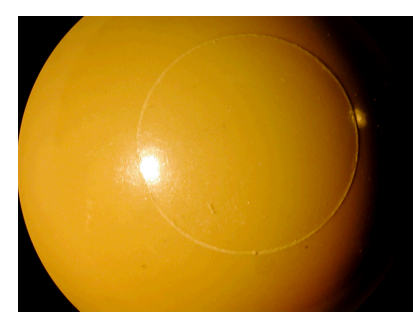

Figure 1. Partial view of a spherical TATB sample (1.26-cm diameter).

Band heaters heat up aluminum anvils to a predetermined temperature at a desired ramp rate before the sample is delivered to the cavity in the center of the aluminum anvils. When the sample is in place, the timer starts. It takes only a fraction of second to heat up the spherical sample to the pre-determined temperature. When the sample temperature exceeds a threshold temperature, thermal decomposition starts. Sample temperature and gas pressure builds up very quickly, resulting in thermal explosion and loud noise that triggers the ODTX timer. For one energetic material, we typically conduct over 10 tests so a chart of time to explosion versus temperature can be constructed, as shown in the experimental results section. After thermal explosion, each aluminum anvil is scanned with a surface profile meter to determine the cavity size expansion. The volume increase of the cavity is an indication of thermal explosion violence. Figure 2 shows the aluminum anvils after the thermal explosion experiment of Semtex $1 \mathrm{H}$ at $173.3^{\circ} \mathrm{C}$.
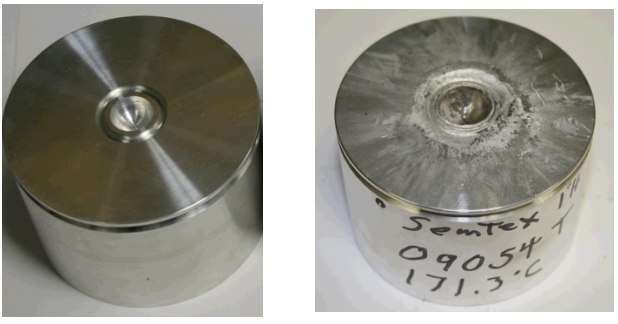

Figure 2: pristine anvil (left); spent anvil (right).

\section{THERMAL SENSITIVITY DATA FOR SOME ENEGETIC MATERIALS}

The times to thermal explosion for several commonly-used high explosives are shown in Figure 3. TATB is less sensitive to thermal ignition than most conventional high explosives. At temperature below $230^{\circ} \mathrm{C}$, a 1.26 -cm spherical pressed part would not thermally explode. Times to explosion data for TNT were similar to those for HMX. PETN is much more sensitive to thermal explosion than TATB, TNT, HMX, and RDX. At 160 C, PETN would explode in 300 seconds but TATB, TNT, HMX, RDX would not explode. The times to thermal explosion for several moldable explosives such as $\mathrm{C} 4$, Semtex 1A and Semtex 1H are shown in Figure 3. In general, the more sensitive ingredient in the formulation dominates the thermal sensitivity. Figure 3 shows the ODTX data for C-4 (RDX and binder) are similar to those of RDX. The thermal sensitivities of Semtex 1A (PETN and Semtex oil, and binder) and Semtex 1H (RDX, PETN, Semtex oil and binder) are very similar to that of PETN.

We have also tested many liquid explosives and the results showed that most of them were more sensitive to thermal explosion than PETN. The error bars of ODTX data for liquid explosives scattered more than those of solid explosives. This is typical of liquid explosives in that they have high vapor pressures and are more volatile. 


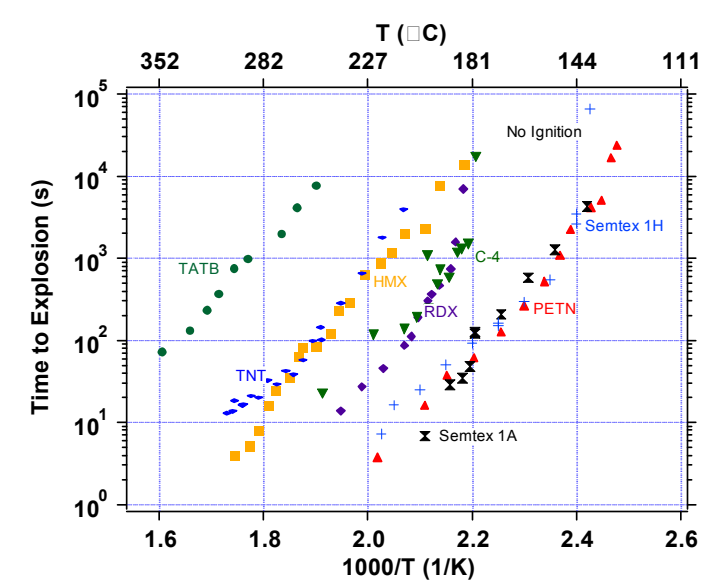

Figure 3. Times to explosion data for some neat and formulated materials.

\section{THERMAL EXPLOSION VIOLENECE}

Violence from thermal explosion is an important parameter for cook off study. After the ODTX testing, each anvil was scanned with a surface profilometer to determine the cavity volume increase, as shown in Figure 2.

Cavity volume increases and relative degree of thermal explosion violence for several materials are listed in Table 1. HMX formulations (e.g. LX-04, 85\% HMX, 15\% binder), with a volume increase of $1.52 \mathrm{cc}$ per gram of sample tested, were the more violent than other energetic materials. TATB had the least thermal explosion violence among the materials listed in table 1 .

A quantitative comparison between thermal explosion violence and detonation violence does not exist. A modeling and experimentation are underway to conduct detonation in confined aluminum anvils to determine the cavity volume increases for several high explosives.

Comparison of thermal explosion violence with detonation violence would become possible.
TABLE 1. Crater volume increases and relative degree of thermal ignition violence

\begin{tabular}{|l|c|c|}
\hline Material & $\begin{array}{l}\text { Average } \\
\text { volume } \\
\text { increase, cc/g }\end{array}$ & $\begin{array}{l}\text { Relative } \\
\text { degree of } \\
\text { violence }\end{array}$ \\
\hline LX-04, pressed & 1.52 & 1 \\
\hline HPP, casted & 0.68 & 0.45 \\
\hline UN/Al, powder & 0.62 & 0.41 \\
\hline LMI, liquid & 0.51 & 0.34 \\
\hline Semtex 1H, paste & 0.19 & 0.13 \\
\hline TATB, pressed & 0.07 & 0.05 \\
\hline
\end{tabular}

\section{DETONATION VIOLENECE MODELING EXPERIMENTS}

We used Zerilli Armstrong constitutive hardening model $^{5}$ to predict the cavity volume increases in aluminum from detonation. The yield stress is a function of temperature and the plastic strain rate. Two detonation experiments were recently completed at ambient temperature with LX-10 sample (95\% HMX, 5\% Viton). The sample was placed in the center of an aluminum anvil with a steel support structure. The LX-10 sample (1.06 grams) was detonated with a chip flyer detonator at very high speed, as illustrated in Figure 4. A current of approximately $30 \mathrm{kA}$ was used to melt and vaporize (explode) a 2-mm copper bridge. When this bridge explodes, it accelerates a $2 \mathrm{~mm}$ by $2 \mathrm{~mm}$ by 127 -um thick Kapton flyer to a velocity around $4 \mathrm{~km} / \mathrm{s}$ as it transverses a $2.5-\mathrm{mm}$ barrel. The barrel is in intimate contact with the LX-10 sample. This flyer hits and promptly initiates the LX-10 test sample.

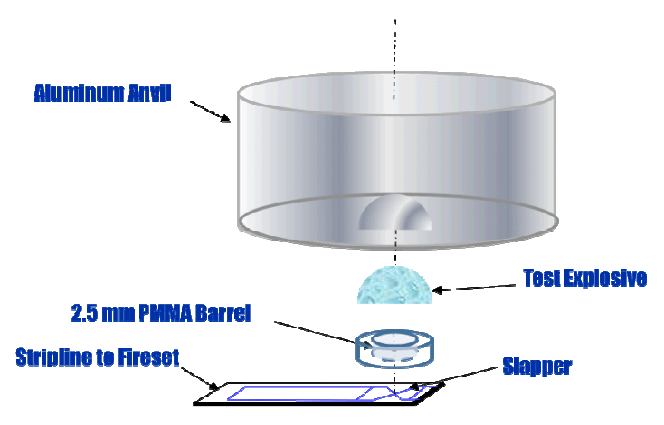

Figure 4. Schematics of initiation mechanism with a high-speed flyer. 
The predicted cavity volume increase in aluminum anvil agreed very well with the experimental results. As shown in Figure 5, the volume expansion predicted from the Zerilli Armstrong model was $2.70 \mathrm{~cm}^{3}$, compared well with the experimental results of $2.73 \mathrm{~cm}^{3}$. The cavity volume increase from detonation was significantly greater than those from thermal explosion, as shown in Table 1.

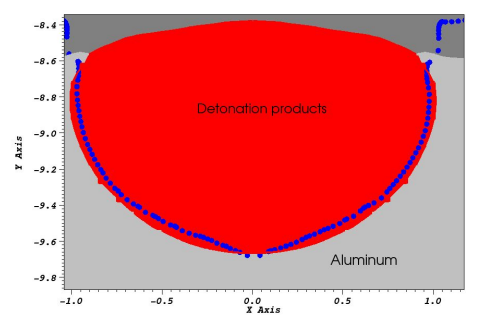

Figure 5. Comparison of cavity volume increases: model prediction in red and experiment in the area circled by blue line.

\section{CONCLUSIONS AND FUTURE WORK}

The ODTX system is a useful tool for the measurements of thermal sensitivity and global thermal decomposition kinetic parameters. Samples of all configurations (solids, powders, pastes, and liquids) can be tested in the system The ODTX testing can also generate useful data for determining relative degree of thermal explosion violence of energetic materials. ZerilliArmstrong constitutive hardening model works well for predicting cavity volume increase in aluminum from detonation. It has been implemented in the ALE3D code. We plan to conduct the detonation experiments in aluminum anvils at high temperatures on LX-10. We also plan to use similar experimental design to verify material models other than aluminum.

\section{ACKNOWLEDGEMENTS}

We would like to thank Sally Weber for preparing pressed parts. The crater volumes were measured by Franco Gagliardi. Funding from DOE is greatly appreciated. This work was performed under the auspices of the U.S. Department of Energy by Lawrence Livermore National Laboratory under Contract DE-AC5207NA27344.

The paper has been reviewed and released for public audience with unlimited distribution. The LLNL review and release number is LLNL-.

\section{REFERENCES}

1. Hsu, P.C., LLNL ODTX System for Thermal Safety Determination of Energetic Materials, LLNL-BR-411732, LLNL report, 2009.

2. Koerner, J. Maienschein, J.L., Burnham, A., and Wemhoff, A., "ODTX

Measurements and Simulations on Ultra Fine TATB and PBX 9502", UCRLConf-232590, LLNL, 2007.

3. Hsu, P.C., Korner, J., Wemhoff, A., Maienschein, J.L., and Reynolds, J., "One-Dimensional Times to Explosion (Thermal Sensitivity) of Energetic Liquid Mixtures", LLNL-TR-404581, 2008.

4. Hsu, P.C., Hust, G. , Howard M., Chidester, S.K., Springer, H.K. and Maienschein, J.L., "The ODTX System for Thermal Ignition and Thermal Safety Study of Energetic Materials", $14^{\text {th }}$ International Detonation Symposium, Coeur d'A;eme, Idaho, April 11-16, 2010.

5. Zerilli, F. J., Armstrong, R.W., "Dislocation-mechanics-based constitutive relations for material dynamics calculation", J. Appl. Phys. 61 (5), 1 March 1987. 